\title{
Antibacterial Activity of Melissa officinalis L., Mentha piperita L., Origanum vulgare L. and Malva mauritiana against Bacterial Microflora Isolated from Fish
}

\author{
Alīna Klūga ${ }^{1}$, Margarita Terentjeva ${ }^{1}$, Attila Kántor ${ }^{2}$, Maciej Kluz ${ }^{3}$, Czeslaw Puchalski ${ }^{3}$, \\ Miroslava Kačániová ${ }^{2,3^{*}}$ \\ ${ }^{1}$ Latvia University of Agriculture, Faculty of Veterinary Medicine, Institute of Food and Environmental \\ Hygiene, K. Helmaña iela 8, Jelgava, LV-3004,Latvia \\ ${ }^{2}$ Slovak University of Agriculture, Faculty of Biotechnology and Food Sciences, Nitra 949 76, \\ Tr. A. Hlinku 2, Slovakia \\ ${ }^{3}$ University of Rzeszow, Faculty of Biology and Agriculture, Zelwerowicza St. 4, 35-601 Rzeszow, Poland
}

\begin{abstract}
The aim of the present study was to detect the antibacterial activity of medicinal plants against fish microflora. A total of 4 ethanolic extracts of 6 plant species were collected from local environments of Slovakia and screened for antibacterial activity against bacterial microflora. Extracts of Melissa officinalis L., Mentha piperita L., Origanum vulgare L. and Malva mauritiana were used. Bacterial strains were isolated from common bleak (Alburnus alburnus) and common rudd (Scardinius erythrophthalmus) of Latvian origin. All bacterial strains were identified with the MatrixAssisted Laser Desorption Ionization-Time of Flight Mass Spectrometry (MALDI-TOF MS). Among fish microflora, Acinetobacter pittii, A. baumannii, Buttiauxella agrestis, Delftia acidovorans, Enterobacter cloacae, Serratia liquefaciens, Pseudomonas alcaligenes, Ps. oryzihabitans, Staphylococcus epidermidis, St. caprae, Pantoea agglomerans, Lelliottia amnigena, Providencia rettgeri, Escherichia coli and Rahnella aquatilis were identified. It has been shown that all plant extracts exhibit different degrees of antimicrobial activity against the tested bacteria. All bacterial strains in the present study were moderate sensitive to all extracts applied. The strongest antimicrobial effect of Malva mauritiana and Melissa officinalis L. against Pseudomonas oryzihabitans (6.67 \pm 1.53 resp. $9.67 \pm 0.58 \mathrm{~mm})$ were found. The best antimicrobial activity of Mentha piperita L. was against Staphylococcus epidermis $(7.33 \pm 0.58$ $\mathrm{mm}$ ) and strongest antimicrobial effect of Origanum vulgare L. was same against two bacterial strains Enterobacter cloacae and Serratia liquefaciens $(9.67 \pm 0.58 \mathrm{~mm})$.
\end{abstract}

Key words: Alburnus alburnus, Scardinius erythrophthalmus, MALDI-TOF MS identification, medicinal plants, disc diffusion method.

\section{Introduction}

Water is the natural habitat of fish, where fish are exposed to permanent contamination with the microorganisms present in surrounding aquatic environment. The microflora consists not only from heterotrophic but also from the contaminants

\section{* Corresponding author: Miroslava Kačániová, miroslava.kacaniova@gmail.com}

(c)) BY-NC-ND 2017 Alina Kluga et al., published by De Gruyter Open. This work was licensed under the Creative Commons Attribution-NonCommercialNoDerivs 3.0 License from municipal and rural run-off and industrial discharges of sewage/faeces [1]. The aquatic microflora influences the composition of microorganisms on fish skin, including the gills. Microorganisms can reach the intestinal tract with water and feed with subsequent colonization. Colonization of fish may start at the egg and larval stage and continue alongside the fish development [2].

Fish microflora was studied intensively and a large variety of the fish inhabiting microorganisms was recognized [3]. 
Traditional herbal medicines are a source of novel antibacterial drugs. Since they are considered as safe for human use, plant based medicines are widely recognized and used for primary health care in developed and developing countries [4, 5]. According to the $\mathrm{WHO}, 60-80 \%$ of the world population applies the traditional treatment [6]. Plants have also been used to get a natural extracts for developing new antimicrobial drugs because of their antimicrobial effect on opportunistic pathogenic and pathogenic microflora. This antimicrobial effect has been shown in food industry on extension of shelf-life of foods [7]. Antimicrobial effect of the medicinal plants is attributable to the content and composition of the plant essential oils (EO), which consist of a large number of secondary metabolites - alkaloids, tannins, and flavonoids $[8,9]$. Since the fish microflora may facilitate fish spoilage and contain opportunistic pathogens and pathogens, the application of the plant extracts can be useful tool to delay the fish microflora development.

The aims of present study were: i) identify the fish microflora with MALDI-TOF MS Biotyper and ii) to test the extracts of medicinal plants against the isolated and identified fish microflora.

\section{Material and Methods \\ Sample collection}

For microbiological analyses, three sample of common bleak (Alburnus alburnus) and three samples of common rudd (Scardinius erythrophthalmus) of Latvian origin were used. Samples were bought on the retail market, placed on ice and transported to the laboratory for the investigations.

\section{Microbiological analyses}

Skin and muscle tissues were used for microbiological testing. Skin samples were taken with sterile swabs from skin surface, but muscle samples were obtained after incision of skin and separation of muscle tissues. The primary dilution was done by adding the peptone buffered water to sample with 1:10 ratio (sample: peptone buffered water). Primary dilution was used for preparation of tenfold dilution.

The total viable count (TVC) and Enterobacteriaceae were detected in samples. TVCs was determined with the pour plate method in plate count agar (PCA, Biolife, Italy) and inoculated plates were incubated at $30{ }^{\circ} \mathrm{C}$ for $48-$ $72 \mathrm{~h}$. on plate count agar, the number of was determined on violet red bile glucose agar (VRBGA), McConkey and Endo agars (Biolife, Italy) were used for detection of
Enterobacteriaceae. Inoculated agars were incubated at $37^{\circ} \mathrm{C}$ for $24-48 \mathrm{~h}$.

After evaluation of bacterial growth, 2-5 colonies from each agar were selected for confirmation with MALDI-TOF MS Biotyper. Bacterial colonies were subcultured on the nutrition agar at $37^{\circ} \mathrm{C}$ for 18-24 $\mathrm{h}$ for identification.

\section{Sample preparation and MALDI-TOF MS measurement}

One colony of each bacterial isolate was transferred into an Eppendorf vial with $300 \mu \mathrm{L}$ of sterile water. Later, the ethanol $(900 \mu \mathrm{L})$ was added to the suspension and mixed well. The suspension was centrifuged (13000 g, $2 \mathrm{~min}$ ), the supernatant was removed and the pellets were dried at room temperature until dry or at least for 5 min. The bacterial pellet was resuspended in 20 $50 \mu \mathrm{L}$ of formic acid (70\% in water) and the same amount of acetonitrile. After centrifugation (2 min at $13000 \mathrm{~g}$ ), an I $\mu \mathrm{L}$ of the supernatant was spotted onto a sample position of a polished steel MALDI target plate and dried at room temperature. Subsequently, $1 \mu$ MALDI matrix (solution of $\alpha$-cyano-4-hydroxycinnamic acid (HCCA) in $50 \%$ acetonitrile/2.5\% trifluoro-acetic acid) was added to the spot and dried again. The MALDI target plate was introduced into the MALDI-TOF mass spectrometer for automated measurement and data interpretation. MALDITOF profile mass spectra were imported into the MALDI Biotyper 3.0 software and processed automatically after measurement. The logarithm of the score (log[score]) was displayed as the matching result. The MALDI Biotyper output was a log(score) between 0 and 3.0, which was calculated from a comparison of the peak list from an unknown isolate with the reference MSP in the database. A log(score) $\geq 1.7$ indicated identification at the genus level, while a log(score) $\geq 2.0$ was set as the threshold for a match at the species level. Isolates with $\geq 2.0$ were accepted as a correct identification.

\section{Preparation of plant extracts}

The plant materials used in this experiment consisted of leaves of Melissa officinalis L., Mentha piperita L., Origanum vulgare L. and Malva mauritiana. The plants were collected in Slovakia. The material was initially dried at the room temperature in the dark. After drying, the plant materials were crushed and an amount of 10 $\mathrm{g}$ of leaves of each plant was soaked separately in $100 \mathrm{~mL}$ of ethanol (99.9\%, Sigma, Germany) for 14 days at room temperature. Then, the ethanolic plant extracts were filtered through the Whatman No. 1 filter paper. After filtration, the obtained extracts were evaporated under reduced 
pressure at $40{ }^{\circ} \mathrm{C}$ in order to remove the ethanol (Stuart RE300DB rotary evaporator, Bibby Scientific Limited, UK, and vacuum pump KNFN838.1.2KT.45.18, KNF, Germany). For the antimicrobial assays, the plant extracts were dissolved in dimethylsulfoxid (DMSO) (Penta, Czech Republic). Stock solutions of plant extracts were stored at $-16{ }^{\circ} \mathrm{C}$ in refrigerator until the experiments were initiated. For experiment, $6 \mathrm{~mm}$ sterilized filter paper discs were impregnated with plant extract.

\section{Detection of antimicrobial activity}

Antimicrobial activity of each plant extract was determined by a disc diffusion method. Briefly, a quantity of $100 \mu \mathrm{L}$ of suspension of the test bacteria were grown in $10 \mathrm{ml}$ of fresh media until the concentration of $10^{5} \mathrm{CFU} / \mathrm{mL}$ was reached. Then, an amount of $100 \mu \mathrm{L}$ of the microbial suspension was spread onto Mueller Hinton agar (Biolife, Italy) and impregnated discs were placed onto surface of inoculated agar. After incubation at 37 for $24 \mathrm{~h}$, the diameters of the inhibition zones were measured. All measurements were to the closest whole millimeter. Each antimicrobial assay was performed in, at least, triplicate. Filter discs impregnated with a $10 \mu \mathrm{l}$ of distilled water were used as a negative control.

Experiments were run triplicate, one colony for each of the three samples of each fish.

\section{Statistical analyses}

For each medicinal plants and pathogenic microorganisms the mean values and the standard deviation were calculated.

\section{Results and Discussions}

Altogether, 15 bacterial species were recovered from fish samples. All the mass spectrometry results indicated good identification on the species with score value from 2.123 to 2.407 for Pantoea agglomerans and Staphylococcus caprae, respectively. All isolated species were identified with $\geq 2.0$ score and this score confirm very good identification. Isolated bacterial species and their MALDI-TOF scores are shown in Table 1.

Identified bacterial species belonged to five different families: Comamonadaceae, Enterobacteriaceae, Moraxellaceae, Pseudomonadaceae and Staphylococcaceae (Table 2). The most abundant bacterial family was Enterobacteriaceae with eight bacterial species isolated but the less abundant Comamonadaceae with one bacterial species isolated. Bacterial strains Acinetobacter pittii, Acinetobacter baumannii, Buttiauxella agrestis, Delftia acidovorans, Enterobacter cloacae, Staphylococcus epidermidis, Staphylococcus caprae were isolated from skin of fish and Escherichia coli, Lelliottia amnigena, Pantoea agglomerans, Pseudomonas alcaligenes, Pseudomonas oryzihabitans, Providencia rettgeri, Rahnella aquatilis, Serratia liquefaciens were isolated from muscles of fish.

Table 1 MALDI-TOF scores of isolated microorganisms

\begin{tabular}{l|c}
\hline Microorganisms & Score value \\
\hline Acinetobacter pittii & 2.351 \\
\hline Acinetobacter baumannii & 2.125 \\
\hline Buttiauxella agrestis & 2.225 \\
\hline Delftia acidovorans & 2.128 \\
\hline Enterobacter cloacae & 2.178 \\
\hline Escherichia coli & 2.156 \\
\hline Lelliottia amnigena & 2.246 \\
\hline Pantoea agglomerans & 2.123 \\
\hline Pseudomonas alcaligenes & 2.229 \\
\hline Pseudomonas oryzihabitans & 2.269 \\
\hline Providencia rettgeri & 2.219 \\
\hline Rahnella aquatilis & 2.355 \\
\hline Serratia liquefaciens & 2.258 \\
\hline Staphylococcus epidermidis & 2.177 \\
\hline Staphylococcus caprae & 2.407 \\
\hline
\end{tabular}

Table 2

Family of the identified bacterial species

\begin{tabular}{l|l}
\hline Microorganisms & Family \\
\hline Acinetobacter pittii & Moraxellaceae \\
\hline Acinetobacter baumannii & Moraxellaceae \\
\hline Buttiauxella agrestis & Enterobacteriaceae \\
\hline Delftia acidovorans & Comamonadaceae \\
\hline Enterobacter cloacae & Enterobacteriaceae \\
\hline Escherichia coli & Enterobacteriaceae \\
\hline Lelliottia amnigena & Enterobacteriaceae \\
\hline Pantoea agglomerans & Enterobacteriaceae \\
\hline Pseudomonas alcaligenes & Pseudomonadaceae \\
\hline Pseudomonas oryzihabitans & Pseudomonadaceae \\
\hline Providencia rettgeri & Enterobacteriaceae \\
\hline Rahnella aquatilis & Enterobacteriaceae \\
\hline Serratia liquefaciens & Enterobacteriaceae \\
\hline Staphylococcus epidermidis & Staphylococcaceae \\
\hline Staphylococcus caprae & Staphylococcaceae \\
\hline
\end{tabular}


The present study revealed the abundance of Enterobacteriaceae and Pseudomonaceae in fish microflora and our finding is in accordance with previously reported [3]. The bacterial microflora of freshwater fish skin have been reported to include Acinetobacter johnsonii [10], aeromonads (notably Aeromonas hydrophila, A. bestiarum, A. caviae, $A$. jandaei, $A$. schubertii, and $A$. veronii biovar sobria [11]), Alcaligenes piechaudii, Enterobacter aerogenes, Escherichia coli, Flavobacterium [12], Flexibacter spp., Micrococcus luteus, Moraxella spp., Pseudomonas fluorescens, Psychrobacter [10] and Vibrio fluvialis $[13,14,15]$. Our study supports the previous observation with isolation of Escherichia, Acinetobacter, Pseudomonas spp. and other bacterial species.

Composition of microflora and occurrence of specific microorganisms may reflect the contamination of fish from surrounding environment [12]. Fish in the present study were bought at the retail market, therefore the occurrence of Escherichia and Staphylococcus may indicate the human presence then the fish could be contaminated during the unhygienic handling on market. In general, the composition of the fish microflora indicates that the fish are prone to spoilage caused by Enterobacteriaceae Rahnella aquatilis, Pantoea agglomerans and Providencia rettgeri and Pseudomonaceae.
Isolation of Acinetobacter baumanii from fish samples is an issue of concern. Despite the environment, including water and soil, is a wellknown habitat of Acinetobacter spp, the microorganisms has been confirmed as an important source of nosocomial infections with extra-hospital reservoirs. Isolation of those opportunistic pathogens from fish shows that $A$. baumanii could spread also with fish.

All the plant extracts tested in the present study were found to show the inhibitory against fish microflora. In our study, the best antimicrobial activity of Melissa officinalis L. was found against Pseudomonas oryzihabitans $(9.67 \pm 0.58)$, Serratia liquefaciens $(7.67 \pm 0.58)$ and Pseudomonas alcaligenes $(6.67 \pm 0.58)$ (Table 3). Melissa officinalis L. (fam. Lamiaceae) is a perennial, aromatic herb native to southern Europe. $M$. officinalis is used widely in food and cosmetics because of the intense lemon aroma and flavor of leaves. M. officinalis leaf extract is known to exhibit the antiviral and antioxidant activity but the essential oil possesses the antibacterial, antifungal and antihistaminic effect [16]. The antibacterial activity of $M$. officinalis has been reported in previously $[17,18]$. In this study, the plant ethanol extract was used. Other researchers showed that the ethanol extract of $M$. officinalis can possess an antioxidant [19] and antinociceptive $\quad$ effect $[20]$.

Antimicrobial activity of medicinal plants extract against bacteria isolated from fish

\begin{tabular}{l|c|c|c|c}
\hline Microorganisms/extract & Malva mauritiana & Melissa officinalis L. & Mentha piperita L. & $\begin{array}{c}\text { Origanum } \\
\text { vulgare L. }\end{array}$ \\
\hline Acinetobacter pittii & $2.67 \pm 0.58$ & $1.67 \pm 1.54$ & $4.67 \pm 0.58$ & $2.33 \pm 0.58$ \\
\hline Acinetobacter baumannii & $2.33 \pm 0.58$ & $3.00 \pm 1.00$ & $2.00 \pm 1.00$ & $1.33 \pm 1.53$ \\
\hline Buttiauxella agrestis & $2.00 \pm 1.00$ & $2.00 \pm 1.00$ & $3.33 \pm 0.58$ & $2.33 \pm 0.58$ \\
\hline Delftia acidovorans & $3.33 \pm 0.58$ & $4.33 \pm 1.15$ & $1.67 \pm 0.58$ & $2.00 \pm 1.00$ \\
\hline Enterobacter cloacae & $1.67 \pm 0.58$ & $5.00 \pm 1.00$ & $6.67 \pm 1.53$ & $9.67 \pm 0.58$ \\
\hline Escherichia coli & $2.67 \pm 0.58$ & $2.33 \pm 0.58$ & $5.33 \pm 0.58$ & $6.67 \pm 1.58$ \\
\hline Lelliottia amnigena & $3.33 \pm 1.53$ & $1.33 \pm 1.53$ & $2.00 \pm 1.00$ & $4.67 \pm 0.58$ \\
\hline Pantoea agglomerans & $2.33 \pm 1.53$ & $2.33 \pm 0.58$ & $1.33 \pm 0.58$ & $3.00 \pm 0.71$ \\
\hline Pseudomonas alcaligenes & $4.67 \pm 0.58$ & $6.67 \pm 0.58$ & $5.33 \pm 0.58$ & $5.67 \pm 0.58$ \\
\hline Pseudomonas oryzihabitans & $6.67 \pm 1.53$ & $9.67 \pm 0.58$ & $5.67 \pm 0.58$ & $7.33 \pm 0.58$ \\
\hline Providencia rettgeri & $1.67 \pm 0.58$ & $2.33 \pm 0.58$ & $3.33 \pm 0.58$ & $1.67 \pm 1.15$ \\
\hline Rahnella aquatilis & $2.00 \pm 0.00$ & $3.33 \pm 1.53$ & $2.67 \pm 0.58$ & $3.00 \pm 1.00$ \\
\hline Serratia liquefaciens & $5.00 \pm 1.00$ & $7.67 \pm 0.58$ & $5.67 \pm 0.58$ & $9.67 \pm 0.58$ \\
\hline Staphylococcus epidermidis & $4.33 \pm 1.15$ & $5.33 \pm 0.58$ & $7.33 \pm 0.58$ & $4.33 \pm 1.15$ \\
\hline Staphylococcus caprae & $5.00 \pm 1.00$ & $3.67 \pm 0.58$ & $5.67 \pm 0.58$ & $5.33 \pm 0.58$ \\
\hline
\end{tabular}


Antimicrobial activity against fish microflora has been shown by Malva mauritiana. The best antimicrobial activity against Pseudomonas

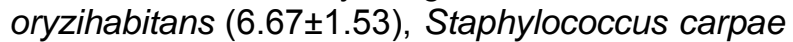

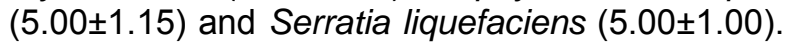
Malva sp., widely known as common mallow, is native to Europe. Application of mallow in traditional medicine has long-time practice, however, little clinical evidence is available. Different parts of plant including roots, leaves, flowers, fruits, and seeds were used for preparation of infusions, decoctions, liniments, lotions, baths and gargles [21,22,23,24,25,26]. Both flowers and leaves were found to show antimicrobial but not antifungal activity [27].

The antimicrobial activity was exhibited by Mentha piperita as well. The best results were found against Staphylococcus epidermidis (7.33 \pm 0.58$)$, Enterobacter cloacae 6.67 \pm 1.53 , Pseudomonas oryzihabitans, Serratia liquefaciens and Staphylococcus caprae (all 5.67 \pm 0.58 ).

Mentha piperita is a perennial plant with worldwide distribution, which is cultivated and wild. Mentha piperita is used for preparation of tea, tinctures, oils or extracts, can be included in rubs or liniments because of it astringent, antiseptic, antipyretic, antispasmodic, anticatarrhal, antimicrobial, rubefacient, stimulant, emmenagogue and antiaging properties [28]. It has been reported, that the leaf extracts were found to be very active against the bacterial strains. Antimicrobial activity was possessed by stem and root extracts as well. Antibacterial properties of leaf and stem extracts were suggested for application in wound healing and septicemia $[29,30]$.

The best antimicrobial activity of Origanum vulgare was found against Enterobacter cloacae, Serratia liquefaciens (both 9.67 \pm 0.58 ) and Pseudomonas oryzihabitans (7.33 \pm 0.58$)$.

Oregano (Origanum vulgare subsp. hirtum) is a herb of the Labiatae family and has been used widely in cooking and traditional medicine. Antimicrobial activity of oregano is related to the the presence of several ingredients, most of which possess antioxidant and antimicrobial properties [31]. Carvacrol and thymol, which comprise about $78-85 \%$ of oregano EOs, are mainly responsible for the antimicrobial activity [32]. Oregano has been reported an effective in modern medicine for inhibition of pathogenic microorganisms and for treatment of infectious diseases [33]. In general, all the medicinal plant extract exhibited the antimicrobial activity indicating the possible application of the extract for prevention of proliferation of microorganisms in fish.

\section{Conclusions}

The present study revealed that the extract from leaves from Melissa officinalis L., Mentha piperita L., Origanum vulgare L. and Malva mauritiana exhibited the antibacterial activity against fish microflora. Pseudomonas oryzihabitans, Serratia liquefaciens, Enterobacter cloacae and Staphylococcus spp. were among the most susceptible bacterial species to the action of plant extracts. In conclusion we recommend use Malvia mauritiana and Melissa officinalis L. extract against Pseudomonas oryzihabitans, Mentha piperita L. against Staphylococcus epidermis and Origanum vulgare L. against two bacterial strains Enterobacter cloacae and Serratia liquefaciens.

\section{Acknowledgements}

The study was supported from the European Community fund project No. 26220220180: Building Research Centre „AgroBioTech" and VEGA 1/0411/17.

\section{References}

1. El-Shafai, S.A., Gijzen, H.J., Nasr, F.A. \& ElGohary, F.A. (2004). Microbial quality of tilapia reared in fecal contaminated ponds. Environmental Research, 95, https://doi.org/10.1016/j.envres.2004.01.002

2. Olafsen, J.A. (2001). Interactions between fish larvae and bacteria in marine aquaculture. Aquaculture, 223-247.

8486(01)00702-5 https://doi.org/10.1016/S0044-

3. Kim, D.-H., Brunt, J.W. \& Austin, B. (2007). Microbial diversity in intestinal contents and mucus in rainbow trout (Oncorhynchus mykiss). Journal of Applied Microbiology, 102(6), 1654-64. https://doi.org/10.1111/j.1365-2672.2006.03185.x

4. Bazzaz, F.B.S., Khajehkaramadin, M. \& Shokooheizadeh, H.R. (2005). In vitro antibacterial activity of Rheum ribes extract obtained from various plant parts against clinical isolates of Gram-negative pathogens. Journal of Pharmaceutical Research, 2, 8791

5. Abu-Irmaileh, B.E. \& Afifi, F.U. (2003). Herbal medicine in Jordan with special emphasis on commonly used herbs. Journal of Ethnopharmacology, 89(2-3), 193-197.

8741(03)00283-6

6. WHO Traditional Medicine Strategy, WHO, Geneva, Switzerland, 2002

7. Kačániová, M., Terentjeva, M., Puchalski, C., Petrová, J., Hutková, J., Kántor, A., Mellen, M., Čuboň, J., Haščík, P., Kluz, M., Kordiaka, R. \& Kunová, S. (2016). Microbiological quality of chicken thighs meat after application of essential oils combination, EDTA and vacuum packing. Potravinarstvo, 10(1), 107-113. https://doi.org/10.5219/548

8. Fernandez, S.P., Karim, N., Mewett, K.N., Chebib, M., Johnston, G.A.R. \& Hanrahan, J.R. (2012). Flavan-3-ol esters: new agents for exploring modulatory sites on GABAA receptors. British Journal of 

$\begin{array}{lcc}\text { Pharmacology, } & \text { 165(4), } & \text { 965-977. } \\ \text { https://doi.org/10.1111/j.1476-5381.2011.01615.x }\end{array}$

9. Tegos, G., Stermitz, F.R., Lomovskaya, O., \& Lewis, K. (2002). Multidrug pump inhibitors uncover remarkable activity of plant antimicrobials. Antimicrobial Agents and Chemotherapy, 46(10), 3133-3141. doi: 10.1128/AAC.46.10.3133-3141.2002

10. Gonzalez, C.J., Santos, J.A., Garcia-Lopez, M.L. \& Otero, A. (2000). Psychrobacters and related bacteria in freshwater fish. Journal of Food Protection, 63, 315-321. https://doi.org/10.4315/0362-028X63.3.315

11. Gonzalez, C.J., Santos, J.A., Garcia-Lopez, M.L., Gonzalez, N. \& Otero, A. (2001). Mesophilic aeromonads in wild and aquacultured freshwater fish. Journal of Food Protection, 64, 687-691. https://doi.org/10.4315/0362-028X-64.5.687

12. Zmyslowska, I., Lewandowska, D., Nowakowski, T. \& Kozlowski, J. (2001). Occurrence of bacteria in water and in vendace (Coregonus albula) during rearing in tanks. Polish Journal of Environmental Study, 10, 5156.

13. Diler, O., Altun, S., Calikusu, F. \& Diler, A. (2000). A study on qualitative and quantitative bacterial flora of the rainbow trout (Oncorhynchus mykiss) living in different fish farms. Turkish Journal of Veterinary Animal Sciences, 24, 251-259

14. Allen, D.A., Austin, B. \& Colwell, R.R. (1983). Numerical taxonomy of bacterial isolates associated with a freshwater fishery. Journal of Genetics Microbiology, 129, 2043-2062

15. Austin, B. (1983). Bacterial microflora associated with a coastal, marine fish-rearing unit. Journal of the Marine Biological Association of the UK, 63, 583-592. DOI: https://doi.org/10.1017/S0025315400070892

16. Stanojevic, D., Cvomic, L.J., Stefanovic, O. \& Solujic Sukdo Sukdolak, S. (2010). In vitro synergistic antibacterial activity of Melissa officinalis L. and some preservatives. Spanish Journal of Agricultural Research, 8(1), 109-115. DOI: 10.2298/ABS1001167S 17. Friedman Henika P.R., Levin C.E. \& Mandrell, R.E. (2004). Antibacterial activities of plant essential oils and their components against Escherichia coli 0157:H7 and Salmonella enterica in apple juice. Journal of Agricultural and Food Chemistry, 52(19), 6042-6048. https://doi.org/10.1021/jf0495340

18. Mimica-Djukic, N., Bozin, B., Sokovic, M. \& Simin, N. (2004). Antimicrobial antioxidant activities of Melissa officinalis L. (Lamiaceae) essential oil. Journal of Agricultural and Food Chemistry, 52(9), 2485-2489. DOI:10.1021/jf030698a

19. Yanishlieva, V.N. \& Marinova, M.E. (2006). Antioxidant activity of selected species of the family Lamiaceae grown in Bulgaria. Nahrung/Food, 39(5-6), 458-464. https://doi.org/10.1002/food.19950390510

20. Guginski, G., Luiz, A.P. \& Silva, M.D. (2009). Mechanisms involved in the antinociception caused by ethanolic extract obtained from the leaves of Melissa officinalis (lemon balm) in mice. Pharmacological Biochemistry and Behavior, 93(1), 10-16. https://doi.org/10.1016/j.pbb.2009.03.014

21. Camejo-Rodrigues, J.S., Ascensão, L., Bonet, M.À. \& Vallès, J. (2003). An ethnobotanical study of medicinal and aromatic plants in the Natural Park of Serra de S. Mamede (Portugal). Journal of Ethnopharmacology, $89, \quad 199-209$. https://doi.org/10.1016/S0378-8741(03)00270-8

22. Natale, A. \& Pollio, A. (2007). Plants species in the folk medicine of Montecorvino Rovella (in land Campania, Italy). Journal of Ethnopharmacology, 109, 295-303. https://doi.org/10.1016/j.jep.2006.07.038 23. Neves, J. M., Matosa, C., Moutinho, C., Queiroz, G. \& Gomes, L.R. (2009). Ethnopharmacological notes about ancient uses of medicinal plants in Trás-osMontes (northern of Portugal). Journal of Ethnopharmacology, 124, 270-283. https://doi.org/10.1016/j.jep.2009.04.041

24. Novais, H.M., Santos, I., Mendes, S. \& PintoGomes, C. (2004). Studies on pharmaceutical ethnobotany in Arrábida Natural Park. Journal of Ethnopharmacology, 93, 183-195. https://doi.org/10.1016/j.jep.2004.02.015

25. Carvalho, A.M. (2005). Etnobotánica del Parque Natural de Montesinho.Plantas, tradición y saber popular en un territorio del nordeste de Portugal. Universidad Autónoma, Madrid.

26. Quave, C.L., Pieroni, A. \& Bennett, B.C. (2008). Dermatological remedies in the traditional pharmacopoeia of Vulture-Alto Bradano, in land southern Italy. Journal of Ethnobiology and Ethnomedicine, 4, 5. https://doi.org/10.1186/1746-42694-5

27. Mihaylova, D., Popova, A., Denkova, R., Alexieva, I. \& Krastanov, A. (2014). In vitro antioxidant and antimicrobial activity of extracts of bulgarian Malva sylvestris L. Conference: First National Conference of Biotechnology, Sofia, 100, 41-48.

28. Ali, M.A., Saleem, M., Ahmad, W., Parvez, M. \& Yamdagni, R. (2002). A Chlorinated Monoterpene Ketone, Acylated-Sitosterol Glycosides and a Flavanone Glycoside from Mentha longifolia (Lamiaceae). Phytochemistry, 59(8), 889-895. https://doi.org/10.1016/S0031-9422(01)00490-3

29. Bhargava, M.K., Singhand, H. \& Kumar, A. (1988). Evalution of Adhatoda vasica as a Wound Healing Agent in Buffa-loes-Clinical Mechanical and Biochemical Studies. Indian Veterinary Journal, 65(1), 33-38.

30. Thaakur, S. R. (2006). Antibacterial Activity of Adhatoda vasica Leaf Extract. Asian Journal of Microbiology Biotechnology and Environmental Science, 8(2), 287-289.

31. Ozkan, G., Sagdic, O. \& Ozcan, M. (2003). Inhibition of pathogenic bacteria by essential oils at different concentrations. Food Science and Technology International, 9 ,

85-8. https://doi.org/10.1177/1082013203009002003

32. Kokkini, S., Karousou, R., Dardioti, A., Krigas, N. \& Lanaras, T. (1997). Autumn essential oils of Greek oregano. Phytochemistry, 44, 883-6. https://doi.org/10.1016/S0031-9422(96)00576-6

33. Masood, N., Chaudhry, A., Saeed, S. \& Tariq, P. (2007). Antibacterial effects of oregano (Origanum vulgare) against gram negative bacilli. Pakistan Journal of Botany, 39(2), 609-613. 